\title{
Desenvolvimento socioeconômico local e reestruturação produtiva paranaense na década de 1990
}

Socioeconomic development and production restructuring

in Paraná in the 1990s decada

\section{Développment socioéconomique et restructuration productive} du Paraná pedant la décennie 1990

Desarrollo socioeconómico y reestructuración productiva del Paraná en la década de 1990

\author{
Christian Luiz da Silva* \\ Wilian Michon Júnior ${ }^{* *}$
}

Recebido em 9/1/2008; revisado e aprovado em 28/2/2008; aceito em 29/2/2008.

\begin{abstract}
Resumo: A abertura de mercado, aliada a atração de investimento por políticas industrias e guerras fiscais dos Estados, como o Paraná, promoveram uma reestruturação produtiva na década da 1990. O objetivo deste artigo foi avaliar as mudanças socioeconômicas e territoriais a partir das transformações produtivas do Paraná e das suas Mesorregiões na década de 1990. A pesquisa foi descritiva, aplicada e quantitativa, com análise dos dados de 1991 a 2000. Concluiu-se que os investimentos foram concentrados na indústria automobilística e na região metropolitana, não propiciando a redução da desigualdade regional.

Palavras-chave: Desenvolvimento local. Paraná. Reestruturação produtiva.

Abstract: In the 1990s decade, market opening plus investments attracted by industrial policies and fiscal war in the Brazilian states, such as Paraná, fostered production restructuring. The present article aims at assessing Paraná socioeconomic and territorial changes based on the production and territorial changes experienced by this state and its meso-regions in the 1990s decade. The article research was descriptive, applied and quantitative and analyzed data from 1991 to 2000. The research inferred that investments were mainly concentrated in the Curitiba metropolitan area car industries, what did not reduce the existing regional unbalance.
\end{abstract}

Key words: Local development. Paraná. Production restructuring.

Résumé: L'ouverture du marché, associée à l'attraction des investissements due aux politiques industrielles et aux guerres fiscales entre les unités de la Fédération brésilienne, telles que le Parana, ont promu une restructuration productive pendant la décennie 1990. L'objectif de cet article a été celui d'évaluer les changements socioéconomiques et territoriaux à partir des transformations productives du Parana et de ses mésorégions pendant la décennie 1990. La recherche a été descriptive, appliquée et quantitative, avec l'analyse de données de 1991 à 2000. On a conclu que les investissements ont été concentrés sur l'industrie automobile et sur la région métropolitaine, et que cela n'a pas favorisé une réduction de l'inégalité régionale.

Mots-clé: Développement local. Paraná. Restructuration productive.

Resumen: La apertura de mercado, en conjunto con la atracción de nuevas inversiones por políticas industriales y guerra fiscal entre los Estados, como Paraná, promoverán una reestructuración productiva en la década de 1990. El objetivo de este artículo fuera evaluar los cambios socioeconómicos y territoriales a partir de las transformaciones productivas del Paraná y de sus regiones en la década de 1990. La pesquisa fuera descriptiva, aplicada y cuantitativa, con análisis de los datos de 1991 hasta 2000. La conclusión es que las inversiones fueran concentradas en la industria automovilística y en la región metropolitana de Curitiba, no habiendo la reducción de la desigualdad regional.

Palabras clave: Desarollo local. Paraná. Reestruturación productiva.

\section{Introdução}

O Paraná passou pela transformação de sua estrutura produtiva seguindo a nova realidade internacional (LOURENÇO, 2003; LOURENÇO, 2000; IPARDES, 2002a; IPARDES, 2002; CASTOR e LEÃO, 2005; VASCONCELOS e CASTRO, 1999). Visando a ampliação quantitativa e qualitativa, as empresas iniciaram uma busca por maior eficiência e escala produtiva para poder com- petir no ambiente globalizado, conforme exposto pelo Consenso de Washington (BAUMANN, 1996; REGO e MARQUES, 2003; SILVA, 2005a)

A reforma da estrutura produtiva foi influenciada expressivamente pela indústria automobilística instalada na Região Metropolitana de Curitiba, por razoes de infra-estrutura, incentivos fiscais e mão de obra (FIRKOWSKI, 2002; SAMPAIO, 2005). Contudo, a atração destas indústrias só foi possí-

\footnotetext{
* Pesquisador - CNPq - Desenvolve o projeto de pesquisa intitulado: Modelo dinâmico de desenvolvimento local para o apoio ao Planejamento Público (processo 40085/2006-3).

** Co-autor do artigo. Economista e pesquisador - CNPq - auxiliar de pesquisa do projeto: Modelo dinâmico de desenvolvimento local para o apoio ao Planejamento Público (processo 40085/2006-3).
} 
vel a partir de pesados incentivos fiscais durante a guerra fiscal entre os estados que visavam ampliar suas estruturas produtivas com indústrias vindas de outras regiões do globo.

A expansão dos investimentos ampliou a taxa de crescimento potencial da oferta industrial, a partir de incrementos na produtividade do setor mais dinâmicos e concorrências, além da redução das margens de lucro da indústria visando se adequar aos preços internacionais competitivos impostos pelos novos players entrantes no mercado (IPARDES, 2002a).

Esta reestruturação produtiva ocorrida durante os anos 1990 possibilitou o crescimento econômico moderado a partir do ano do segundo qüinqüênio desta década. Embora as teorias clássicas de desenvolvimento preconizassem que o crescimento econômico gera automaticamente o desenvolvimento da sociedade, através da geração da renda, novas teorias apresentam que o desenvolvimento possui um conceito mais amplo que o crescimento (BELLEN, 2004; CAMARGO, 2003; CLAYTON e RADCLIFFE, 1996; DRESNER, 2002; FOLADORI, 2002; GRAFF et al., 1996; HAQUE, 2000; SACHS, 1986; SACHS, 1993; SILVA, 2005b; SOUZA, 1999). Deste modo, é necessário questionar como as transformações produtivas impactaram no processo de desenvolvimento local da sociedade paranaense. A importância do conceito local se desenvolve, principalmente, ao se tratar a dinâmica territorial (VAZ, 1995), como pressuposto neste artigo.

Essa pesquisa busca compreender a dinâmica das mesorregiões paranaenses a partir das mudanças no padrão industrial na década de 1990, que também serão fruto de avaliação neste trabalho. $\mathrm{O}$ objetivo do artigo é avaliar as mudanças socioeconômicas e territoriais a partir das transformações produtivas do Paraná e das suas mesorregiões na década de 1990. A principal limitação é tratar o processo de desenvolvimento local somente pela ótica socioeconômica, a partir da sua delimitação e dinâmica espacial ou territorial.

Esse artigo está organizado em seis seções, incluindo esta introdução. A segunda seção apresentará a fundamentação teórica baseada em teorias de desenvolvimento econômico, mostrando evolução de conceitos até a discussão do desenvolvimento sustentável e suas dimensões. A terceira seção apresentará a metodologia de pesquisa e a quarta seção contextualizará o período analisado com a evolução de alguns indicadores representativos da macroeconomia paranaense na década de 1990. A quinta seção tratará da comparação das transformações entre as mesorregiões do Paraná separadas entre as dimensões do desenvolvimento sustentável, visando discutir o problema em questão neste artigo. A sexta seção trará as conclusões e proposta de novos trabalhos.

\section{Desenvolvimento local: controvérsias a partir da estrutura produtiva}

Soto Torres e Fernandez Lechón (2006) não discutem a influência do Estado no processo de desenvolvimento local, mas revisam os estudos sobre crescimento econômico e ressaltam que novos elementos têm sido avaliados, como a influência específica dos fatores do crescimento contínuo. Os autores citam, contudo, que "there are models constructed only by using statistical methods and econometric techniques and in other cases, the researches use particular insights in order to capture aspects of a complex reality" (SOTO TORRES e FERNANDEZ LECHÓN, 2006 , p. 2). Como contraponto os autores citam Sterman para explicar que alguns estudos desses modelos mostram que um número significativo de variáveis é interconectado pela influência causal que gera um processo de feedback, o que explica o processo de acumulação inerente a qualquer crescimento.

Essa contribuição ressalta que o desenvolvimento local é um processo dependente dos recursos pertencentes, das decisões tomadas e dos acontecimentos passados. As ações presentes pertencem a história e implicam no futuro. Ao considerar o processo de desenvolvimento local somente como resultado dos recursos disponíveis e na sua perfeita combinação, como ressaltado por Soto Torres e Fernandez Lechón nos modelos estatísticos e econométricos tradicionais, perdese a componente histórica e de retroalimentação da ação presente sobre o futuro.

Os modelos de planejamento e desenvolvimento local surgem com o objetivo de mostra que a história pode ser diferente da 
tendência, quando ações são executadas para mudá-las. O processo de planejamento e implementação de modelos de desenvolvimento local é antagônico e controverso pela estrutura da sociedade. Mercado e Córdova (2005) recontam a história controversa entre o desenvolvimento sustentável e a indústria e mostram diversos dilemas e diferenças entre o discurso e a prática do desenvolvimento sustentável, como, por exemplo, sobre a ecologia global:

... durante los noventa, ... se presenciaron procesos político-ecónomicos suficientemente antagónicos como para frenar el proceso de conformación de la nueva cultura ambiental industrial que comenzaba a avizorarse. De una parte, digamos positiva, podría destacarse la considerable ampliación de la preocupación ambiental en la sociedad (y) ... hacían posiblen o sólo la disminución del impacto ambiental de la actividad industrial sino también proponer nuevas formas de producción y hasta de consumo... Por la otra, digamos negativo, estarían el decaimiento significativo del ímpetu de dicha participación debido a que muchas de las oportunidades fueron cerradas a inicios del nuevo siglo, fundamentada por presiones del 'mercado' y disminución de respaldo por parte del Estado (MERCADO e CÓRDOVA, 2005, p. 37).

Silva (2005b, p. 15) avança sobre esta controvérsia e argumenta que "a diferença entre o discurso e a prática ainda continua gerando conflito porque, em ambas óticas (capitalista e ambientalistas), ao refletir sobre o longo prazo, a zona de negociação é menos árida do que no curto prazo. Por exemplo, negociar que a geração futura tem de preservar para sobreviver é muito mais simples do que acordar que essa geração preservará o meio ambiente e não utilizará formas degradantes para os recursos". Essa diferença entre o discurso e a prática do desenvolvimento sustentável é minimizada no âmbito da discussão, segundo Vivien (2005), pela sua retórica dominante. $\mathrm{O}$ autor menciona que "Il est courant de présenter lê développment soutenable comme la solution aux problèmes rencontrés par lês sociétés contemporaines. (...). Il cachê (...) une volonté grandissante de nier les conflicts, de passer outre les divergences et d'aligner les arguments contradictoires" (VIVIEN, 2005, p. 4). Os autores retomam tal controvérsia para relativizar os dogmas criados em torno de um conceito, que ressalta mais a existência de um problema do que uma solução.

A despeito desse dilema em discussão, o processo de desenvolvimento das regiões deve considerar ambas óticas (econômica e ambiental), valendo-se da presente retórica do desenvolvimento sustentável, cuja complexidade é incontestável e inerente as suas implicações geopolíticas (AJARA, 2003, p. 9). Neste sentido, deve-se limitar o processo de desenvolvimento ao local que está sendo analisado. Para Froehlich (1998, p. 95)

o espaço passa hoje a desempenhar um papel crucial para se pensar o desenvolvimento, pois a própria sociedade só é concreta com o espaço, sobre o espaço, no espaço. Espaço agora multifacetado, porque se considera que, só pensado enquanto multidimensional, pode ser autêntico o desenvolvimento. (...) É neste âmbito argumentativo que se pode considerar válido atribuir um sentido 'localista' ao desenvolvimento, podendo-se falar em algo como 'desenvolvimento local'. (grifo nosso)

Blakely (1994) explica que o desenvolvimento econômico desse local tem ênfase no "desenvolvimento endógeno", utilizando-se do potencial humano local, institucional e recursos físicos. O autor ocupa-se apenas da dimensão econômica do desenvolvimento e diz que o desenvolvimento econômico local é um processo-orientado. "That is, it is a process involving the formation of new institutions, the development alternative industries, the improvement of the capacity of existing employers to produce better products, the identification of new markets, the transfer of knowledge, and the nurturing of new firms and enterprises" (BLAKELY, 1994, p. 50). Esse autor torna o processo de desenvolvimento algo inerente ao próprio local e específica o papel da intervenção pública para o provimento das necessidades para o estabelecimento da indústria privada, que, a partir da orientação e dinâmica dos agentes e instituições locais, seriam os responsáveis pelo processo de desenvolvimento.

Souza (1997, p. 19) também entende esta noção de desenvolvimento como "um movimento (sem fim - ou seja, sem 'estágio final' ou mesmo direção concreta predeterminados ou previsíveis e que não poderá ja- 
mais ser declarado como 'acabado' - e sujeito a retrocessos) em cuja esteira uma sociedade torna-se mais justa e aceitável para seus membros" (grifo nosso).

A posição de ambos autores, Blakely e Souza, enfatizam o papel dos agentes locais em detrimento a participação do Estado, colocando o tema no estágio de discussão proposto por Mattos, citado em Froehlich (1998), sobre a descentralização do poder. Neste artigo considera-se que o processo de desenvolvimento local é endógeno e orientado, como citado por Blakely, em movimento, como exemplificado por Souza, mas influenciado pela intervenção do Estado. A participação deste agente pode ser ativa, como agente e investidor, ou institucional, como regulador, mas é interveniente no processo de desenvolvimento local, como o foi na década de 1990 com a política industrial adotada (SILVA e FARAH Jr, 2004).

Contudo, esse desenvolvimento endógeno, apesar de estar relacionado ao processo de interveniência do Estado, pode ser alterado e em virtude dos objetivos nacionais estabelecidos no planejamento público para a região. A década de 1990 teve reflexos da política industrial do Estado que foi determinante para o processo de reestruturação produtiva do Paraná. Esta reestruturação, contudo, ocorre a partir de uma lógica histórica e seu impacto não se desprende do passado para formar um novo futuro, como salienta Lencioni.

Isso significa que a compreensão da reestruturação produtiva e da extensão territorial do processo de metropolização não pode ter como referência uma totalidade fechada; até porque há uma lógica histórica em sua constituição que precisa ser apreendida. A compreensão dessa lógica histórica é fundamental para se entender o processo de reestruturação produtiva e, não, a apreensão de todos os elementos dessa totalidade. (...) Em suma, e parodiando, o termo reestruturação produtiva tem que se colocar em seus devidos termos; ou seja, entendido como uma estruturação nova que se impõe à antiga e, ao mesmo tempo contém germes de um futuro. Pensado, portanto como uma totalidade dialética e não sistêmica, em processo e não acabada. (LENCIONI, 2003, p. 1).

A intensa modernização da base produtiva do Estado e a sua concentração em alguns pólos regionais definiu historicamente os contornos dessas disparidades, segundo Ipardes (2004). Apesar do novo ciclo de investimento, a questão é como ocorreu este processo de reestruturação produtiva e, principalmente, se houveram mudanças socioeconômicos para os municípios paranaenses a partir desta base produtiva. A próxima seção apresenta a metodologia para avaliação destas mudanças, para na seção posterior contextualizar o ambiente competitivo no Estado no período analisado e em seguida avaliar os impactos socioeconômicos por mesorregião.

\section{Metodologia de pesquisa}

A pesquisa foi principalmente descritiva, aplicada e quantitativa. A hipótese deste artigo é que embora os dados agregados do Paraná tenham mostrado melhorias em 2000 em relação a 1991 a mudança ficou concentrada na região metropolitana de Curitiba e nas grandes cidades. A validação da hipótese ocorrerá pela avaliação comparativa de indicadores socioeconômicas selecionados por mesorregião.

No tocante aos seus objetivos, foi descritiva quando relatou as as principais transformações produtivas na década de 1990 e as mudanças ocorridas em indicadores socioeconômico selecionados para esta década por mesorregião (MARKONI e LAKATOS, 1996) ${ }^{1}$.

A técnica quantitativa foi utilizada para estruturar os dados coletados para o período analisado com intuito de compreender as transformações ocorridas por mesorregião (GIL, 1999). Os dados utilizados são agregados socioeconômicos e indicadores de desenvolvimento humano para as delimitações territoriais trabalhadas, como: Índice de Gini, Theil, IDH-M, taxas de mortalidade e natalidade, níveis de educação, taxa de analfabetismo, densidade demográfica, grau de urbanização, taxa de crescimento populacional, cobertura de vacinação, despesas municipais, empregos por indústrias, número de estabelecimentos, consumo de energia, produção da silvicultura, abastecimento de água, atendimento de esgoto, dentre outros. 
A coleta de dados ocorreu por levantamento nos sítios da Internet do IBGE, IPARDES, IPEA, PNUD e Ministério das Cidades. O período dos dados coletados se limita a década de 1990 nos seus extremos (1991 e 2000), vinculando ao momento anterior dos novos investimentos (1991) e após a sua consolidação (2000). Utilizou-se a técnica univariada (gráficos e tabelas com freqüência simples). Testou-se também a técnica bivariada (correlações simples), mas não resultou em informações incrementais que justificassem a sua apresentação e análise.

\section{Evolução socioeconômica e espacial do Paraná na década de 1990}

Ao longo dos anos 1990, a economia e a indústria paranaense, impulsionadas pela retomada e transformações da economia brasileira, demonstrou uma ampliação quali- tativa e quantitativa nas suas bases de operação. Esta expansão da base industrial, iniciada nos anos 1970, foi liderada pela indústria automobilística, e associou-se a fortes incrementos de produtividade, decorrentes de inversões para reposição dos bens de capitais mais intensamente depreciados, uma vez que a produtividade e preços internacionais passaram a determinar a viabilidade econômica de um empreendimento no novo ambiente concorrencial (LOURENÇO, 2003; IPARDES, 2002a; FIRKOWSKI, 2002).

Os ganhos de eficiência possibilitaram a racionalização dos recursos humanos e a desverticalização das unidades produtivas, para que a empresa esteja focada no core business, com ganhos de competitividade, advindo da redução expressiva da alíquota de importação e da estabilidade de preços, que resultaram no aumento da competição e na redução das margens de lucro, conforme ilustra o gráfico 1 (IPARDES, 2002a).

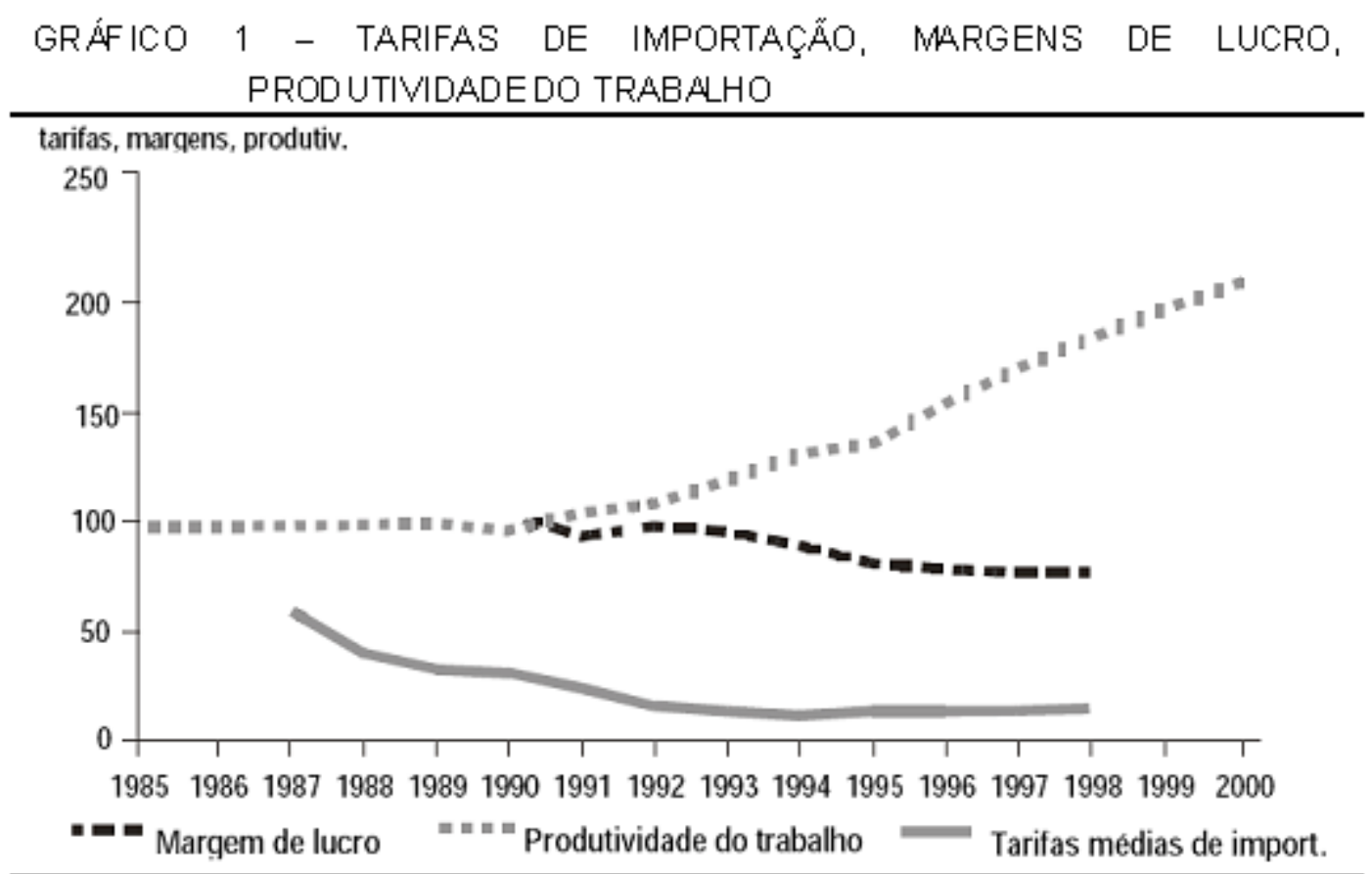

FONTE: IPARD ES (2002).

Silva e Farah Jr. (2004, p. 19) discutem a política industrial do Paraná na década de 1990 para atração de novos investimentos a partir do retardamento do recolhimento do ICMS (imposto sobre circulação de mercadorias e serviços) para quem realizasse investimentos fixos no Estado. Tal política foi caracteriza pelos autores como
(...) ações de política industrial horizontal e vertical. A principal ação horizontal é a busca pela desconcentração industrial e regional, além da modernização tecnológica. Já a política vertical está relacionada aos setores privilegiados (mecânico, material elétrico e de comunicações, material de transporte e química). O programa, entretanto, não deixa claro as regras para beneficiamento, nem 
a definição de indicadores de acompanhamento, nem a transparência da concessão dos benefícios.

Segundo a classificação utilizada por Castro (2002) pode-se verificar o crescimento na participação do grupo tecnológico, o que caracterizou um dos benefícios e resultados trazidos pela reconfiguração produtiva paranaense da década de 1990. Essa reconfiguração foi, impulsionada principalmente pelo crescimento da indústria automotiva, que cresceu 9,4 pontos percentuais na participação do valor adicionado paranaense. O grupo fornecedor apresentou crescimento mais moderado de 3,9 pontos percentuais na participação do valor adicionado, com destaque para a indústria petroquímica que saltou de $10,3 \%$ para $24,3 \%$ e a redução da agroindústria de $17,7 \%$ para $4,5 \%$ entre 1985 e 2000. O grupo tradicional perdeu participação no valor adicionado estadual, caindo 12,1 pontos percentuais puxados pela indústria de alimentos (tabela 1).

\begin{tabular}{|c|c|c|c|c|}
\hline \multirow{2}{*}{ GRUPO INDUSTRIAL } & \multicolumn{4}{|c|}{ DISTRIBUICẤO } \\
\hline & 1985 & 1990 & 1995 & 2000 \\
\hline TOTAL GERAL & 100,0 & 100,0 & 1000 & 100 \\
\hline Grupo Tecnológico & 20,9 & 260 & 30,0 & 29,0 \\
\hline Eletroeletrônica e telecomunic açốes & 3,2 & 7,3 & 12,5 & 7,0 \\
\hline Máquinas e equipamentos & 9,1 & 7,0 & 4,2 & 3,4 \\
\hline Automotia & 2,2 & 8,4 & 9,1 & 11,6 \\
\hline Produtos químicos & 6,4 & 3,3 & 4,3 & 6,9 \\
\hline Grupo Forn ecedor & 44,2 & 498 & 43,6 & 48,1 \\
\hline Extr ativa e minerais nẫo-metálicos & 3,2 & 7,7 & 6,0 & 5,2 \\
\hline Siderurgia e metalurgia & 2,1 & 3,7 & 2,6 & 2,7 \\
\hline Petroquímica & 103 & 16,6 & 13,5 & 24,3 \\
\hline Madeira & 6,9 & 5,2 & 5,3 & 5,0 \\
\hline Papel e gráfica & 3,9 & 4,3 & 8,3 & 6,5 \\
\hline Agroindústrias & 17,7 & 122 & 7,9 & 4,5 \\
\hline Grupo Tradicional & 349 & 242 & 26,4 & 22,8 \\
\hline Aimentos & 27,3 & 120 & 12,7 & 9,1 \\
\hline Couros e peles & 0,8 & 1,6 & 0,9 & 0,6 \\
\hline Malharia e confecçỗes & 1,3 & 0,6 & 1,8 & 1,5 \\
\hline Bebidas & 1,6 & 3,1 & 4,3 & 2,9 \\
\hline Mobiliário & 2,3 & 4,2 & 3,2 & 2,8 \\
\hline Artefatos de papel e papelẫo & 0,6 & 1,1 & 1,2 & 3,0 \\
\hline Artigos de matéria plástica & 1,0 & 1,6 & 2,3 & 3,0 \\
\hline
\end{tabular}

FONTE: IPARDES.

NOTA:Dados extrádos de Castro (2002).

A maior participação do grupo tecnológico foi direcionado pela estratégia de participação da cadeia global, que trouxe investimentos para exportação. A pauta de exportações paranaenses evidencia estas transformações competitivas do sistema produtivo do Paraná, em especial o grupo tecnológico direcionado pela indústria automobilística, que incrementou a sua participação de $4,1 \%$ para $18,7 \%$ em 2000 , em detrimento, principalmente, do grupo fornecedor, representada pela indústria petroquímica (tabela 2). 


\begin{tabular}{|c|c|c|c|c|c|}
\hline \multirow{2}{*}{ GRUPO INDUSTRIAL } & \multicolumn{5}{|c|}{ DISTRIBUICÁA\% } \\
\hline & 1990 & 1995 & & 1999 & 2000 \\
\hline Total da Indústria & 100,0 & 100,0 & 100,0 & 100,0 & 100,0 \\
\hline Grupo Tecnológico & 12,2 & 13,7 & 22,7 & 26,8 & 29,0 \\
\hline Eletroeletrônica e telecol & 2,3 & 2,1 & 10,1 & 6,4 & 4,9 \\
\hline Máquinas e equip amentos & 5,1 & 5,5 & 5,5 & 5,3 & 4,0 \\
\hline Automotiva & 4,1 & 5,4 & 5,8 & 14,3 & 18,7 \\
\hline Produtos & 0,8 & 0,6 & 1,3 & 0,9 & 1,4 \\
\hline Grupo Fom & 58,3 & 63,1 & 56,2 & 52,2 & 47,8 \\
\hline Extrativa & 2,7 & 3,4 & 3,1 & 1,7 & 1,9 \\
\hline Siderurgi & 0,7 & 1,5 & 2,2 & 2,9 & 5,2 \\
\hline Petroquí mica & 15,3 & 4,6 & 2,8 & 0,4 & 0,7 \\
\hline Madeira & 4,2 & 7,9 & 9,9 & 11,4 & 11,2 \\
\hline $\begin{array}{l}\text { Papel e gráfica } \\
\text { Aqroindústria }\end{array}$ & $\begin{array}{r}2,8 \\
32,6\end{array}$ & $\begin{array}{r}8.7 \\
36.9\end{array}$ & $\begin{array}{r}4,0 \\
34.3\end{array}$ & $\begin{array}{r}3,8 \\
32,0\end{array}$ & $\begin{array}{r}3,7 \\
25,2\end{array}$ \\
\hline Grupo $T$ & 29,5 & 23,3 & 21,1 & 21,0 & 23,2 \\
\hline Aimen & 13,9 & 11,7 & 7,7 & 5,5 & 9,6 \\
\hline Courc & 14,2 & 7,1 & 5,2 & 4,5 & 5,1 \\
\hline Malharia e conf ecçōe & 0,1 & 0,8 & 1,0 & 0,6 & 1,2 \\
\hline Bebidas & 0,0 & 0,0 & 0,1 & 0,1 & 0,1 \\
\hline Mobiliáric & 0,3 & 1,9 & 1,9 & 2,0 & 2,7 \\
\hline Artefatos de $\mathrm{F}$ & 0,3 & 0,4 & 0,7 & 0,6 & 1,7 \\
\hline Artigos de matérias plásticas & 0,7 & 1,3 & 4,6 & 7,8 & 2,9 \\
\hline
\end{tabular}

FONTE: IPARDES

Essas transformações resultaram em um processo de reestruturação produtiva, nos moldes expostos por Lencioni (2003), ou seja, uma estruturação nova que se impõe à antiga, pensado com uma totalidade dialética da dinâmica territorial e em processo inacabado. Esse crescimento ocorreu na região metropolitana de Curitiba, principalmente, onde já havia uma base metalmecânica estabelecida desde 1970 (FARAH, 2002). A próxima seção tratará das mudanças locais, próprias da dinâmica territorial paranaense, a partir das alterações produtivas paranaenses na década de 1990.

\section{Avaliação comparativa das mesorregiões paranaenses nos anos 1990}

As diferenças das mesorregiões geográficas do Paraná são oriundas da estrutu- ra heterogênea em relação a sua própria formação, ou seja, a composição municipal, populacional, grau de urbanização, crescimento populacional, participação na renda da economia do Estado e empregabilidade (tabela 3). A região centro-ocidental, por exemplo, é composta de apenas 25 municípios, com taxa de crescimento populacional negativa, moderado grau de urbanização (73\%) e participação de apenas $2,2 \%$ do valor adicional. Em contrapartida a região norte central tem 79 municípios, a população cresce a uma taxa de $1,2 \%$, com alta taxa de urbanização (88\%) e representa $14 \%$ do valor adicionado do Estado. Assim, como menciona Lencioni (2003) a divergências das mesorregiões são frutos de um processo histórico e já estavam presentes no início da década de 1990, antes do novo ciclo de investimentos produtivos no Estado. 
TABELA 3-INDICADORES SELE CIONADOS - 2000

\begin{tabular}{|c|c|c|c|c|c|c|}
\hline MESORFE GIÄO & $\begin{array}{l}\text { NÚMERO DE } \\
\text { MUNCÍPIOS }\end{array}$ & $\begin{array}{c}\text { POPULACẤ. } \\
\text { TOTAL }\end{array}$ & \begin{tabular}{|c|} 
TAXA CRE SC. \\
POP. TOT AL \\
1991_2mO \\
\end{tabular} & $\begin{array}{c}\text { GRML DE } \\
\text { LREMNIZAÇẤO }\end{array}$ & $\begin{array}{l}\text { PARTICIPACAONO } \\
\text { VALOR ADICIONADO } \\
\text { FISCM DOESTADO }\end{array}$ & $\begin{array}{c}\text { TAXA DE } \\
\text { DESEMP FEGO }\end{array}$ \\
\hline Centro-ocidental & 25 & 346.648 & $-1,24$ & 72,6 & 2,2 & 13,7 \\
\hline Centroorierta & 14 & 623.356 & 1,46 & 81,2 & 76 & 14,1 \\
\hline Centro-Su & 29 & 533.317 & 0,69 & 60,9 & 39 & 11,5 \\
\hline Metropolitara de Curtiba & 37 & 3053.313 & 313 & 90,6 & 459 & 147 \\
\hline Noroest & 61 & 641.084 & $-0,25$ & 77,3 & 3,7 & 10,7 \\
\hline Norte Certral & 79 & 1829.068 & 1,24 & 88,4 & 14,3 & 12,4 \\
\hline Norte Pionero & 46 & 548.190 & $-0,15$ & 75,1 & 28 & 11,9 \\
\hline Oese & 50 & 1.138 .582 & 1,28 & 81,6 & 138 & 12,8 \\
\hline Sudeste & 21 & 377.274 & 0,89 & 53,6 & 23 & 9 \\
\hline Sudoeste & 37 & 472.626 & $-0,13$ & 59,9 & 35 & 8,4 \\
\hline PARAN厽 & 399 & 9563.458 & 14 & 814 & 10 & 128 \\
\hline
\end{tabular}

A distribuição das mesorregiões no Paraná auxilia a compreensão da dinâmica populacional e suas principais atividades econômicas. O Paraná possui 199,88 mil quilômetros quadrados, sendo que 11,6\% desta área situam-se na região metropolitana de Curitiba, responsável por quase um terço da população do estado. O processo de urbanização comentado anteriormente está presente em todas as mesorregiões do estado, principalmente na região sul do estado, onde a população apresenta menor grau de urbanização do estado (tabela 4).

T AEE LA 4-P OPULAÇẪO DAS MESORRE GIỐES E DEN SGDADE DE MOGRÁFICA 1991-2000.

\begin{tabular}{|c|c|c|c|c|c|c|c|c|c|}
\hline \multirow{2}{*}{ LOCAUDADE } & \multicolumn{2}{|c|}{ AREA } & \multicolumn{3}{|c|}{ POPU_AC } & \multicolumn{2}{|c|}{ DENSID ADE $/ H A B N M^{2}$} & \multicolumn{2}{|c|}{ 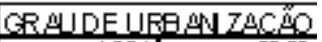 } \\
\hline & Buse & $\% \mathrm{PR}$ & 1991 & 200 & $\Delta \%$ & 1991 & 2000 & 1991 & 200 \\
\hline $\begin{array}{l}\text { Centr oOdicertal Parara日se } \\
\text { Centr oOriental P aranarse }\end{array}$ & $\begin{array}{l}11.938 \\
21.812\end{array}$ & $\begin{array}{r}6,0 \% \\
109 \%\end{array}$ & $\begin{array}{l}387.451 \\
547.559\end{array}$ & $\begin{array}{l}346.648 \\
623.76\end{array}$ & $\begin{array}{r}-10,9 \% \\
13,8 \%\end{array}$ & $\begin{array}{l}32,5 \\
25,1\end{array}$ & $\begin{array}{l}29,0 \\
28,6\end{array}$ & $\begin{array}{l}61,0 \% \\
73,9 \%\end{array}$ & $\begin{array}{l}72,6 \% \\
81,2 \%\end{array}$ \\
\hline Centr oSuP aranaense & 26.439 & $13,2 \%$ & 501.428 & 533.317 & $6,4 \%$ & 19,0 & 20,2 & $48,2 \%$ & $00,9 \%$ \\
\hline Metropditana de Qurtiba & 23.147 & $11,6 \%$ & 2.319 .526 & 3053.313 & $31,6 \%$ & 100,2 & 1319 & $89,4 \%$ & $90,6 \%$ \\
\hline Noreste Parange & 24.750 & $12,4 \%$ & 655.509 & 641.084 & $-2,2 \%$ & 26,5 & 25,9 & $67,4 \%$ & $7,3 \%$ \\
\hline Nate Certral Paranaense & 24.554 & $12,3 \%$ & 1.638 .677 & 1829.068 & $11,0 \%$ & & 74,5 & $81,4 \%$ & $88,4 \%$ \\
\hline Nate P ioreir oParananse & 15.719 & $7,9 \%$ & 555.339 & 548.190 & $-1,3 \%$ & & 34,9 & $64,3 \%$ & $7,1 \%$ \\
\hline Oeste Paranense & 22.865 & $11,4 \%$ & 1.016 .481 & 1.138 .882 & $12,0 \%$ & 44,5 & 49,8 & $71,7 \%$ & $81,0 \%$ \\
\hline SudesteParamaense & 17.011 & $85 \%$ & 348.617 & 377.74 & $8,2 \%$ & 20,5 & 22,2 & $44,2 \%$ & $53,8 \%$ \\
\hline Sudoeste $\mathrm{Pa}$ anarвe & 11.646 & $5,8 \%$ & 478.126 & 472.626 & $-1,2 \%$ & 41,1 & 40,6 & $47,2 \%$ & $\$ 9,9 \%$ \\
\hline PARAKÁ & 199.880 & $10 \mathrm{0} 0 \%$ & 8.448 .713 & 9.563 .458 & $13,2 \%$ & 42,3 & $\mathbf{4}, 8$ & $73,4 \%$ & $81,4 \%$ \\
\hline
\end{tabular}

F ONTE: IP ARDES.

O crescimento da população entre 1991 e 2000 foi muito acentuado na mesorregião metropolitana de Curitiba, e em menor escala nas mesorregiões onde há grandes cidades, como Londrina e Maringá no Norte Central do Paraná. Isto se deve em parte pelo processo migratório entre mesorregiões e interestadual, em que muitas pessoas que moravam no interior paranaense migraram para as cidades, principalmente Curitiba e poucos para Londrina e Maringá. A tabela 5 apresenta o fluxo migratório intermesorregional e interestadual no Paraná entre 1995 e 2000. 
TAEE LA 5-F LUXO MIGRATÓ RIO-1995/2000.

\begin{tabular}{|c|c|c|c|c|c|c|c|c|c|}
\hline \multirow[b]{2}{*}{ MESORREGIỐES } & \multicolumn{3}{|c|}{ |MAlGRANTFS } & \multicolumn{3}{|c|}{ FMLGR MUTES } & \multicolumn{3}{|c|}{ IROCAS ل́⿴囗十⺝ } \\
\hline & $\begin{array}{c}\text { Intem esor- } \\
\text { recional }\end{array}$ & |Irterestaduais & TOTAL & \begin{tabular}{|c|} 
Intemesor- \\
recional
\end{tabular} & Interestaduais & TOT AL & \begin{tabular}{|c|} 
Intemeso' - \\
reringat
\end{tabular} & Irteres aduais & TOT \\
\hline $\begin{array}{l}\text { Centro-Ocidenta } \\
\text { Centro-Oriertal }\end{array}$ & $\begin{array}{l}13.661 \\
22.261\end{array}$ & $\begin{array}{r}7.437 \\
10.313\end{array}$ & $\begin{array}{l}21.098 \\
32.573\end{array}$ & $\begin{array}{l}33.168 \\
24.906\end{array}$ & $\begin{array}{r}20.000 \\
9.263\end{array}$ & $\begin{array}{l}53.168 \\
34.168\end{array}$ & $\begin{array}{r}-19.506 \\
-2.645\end{array}$ & $\begin{array}{r}-12.563 \\
1.050\end{array}$ & $\begin{array}{r}-3207 \\
-1.58\end{array}$ \\
\hline Centro-Sul & 20.218 & 8.490 & 28.708 & 31.934 & 16.681 & 48.615 & -11.716 & -8.192 & $2-199$ \\
\hline $\begin{array}{l}\text { Metrop. de Curiba } \\
\text { Nơde } \\
\text { Note Central }\end{array}$ & $\begin{array}{r}133.124 \\
23.045 \\
60.726\end{array}$ & $\begin{array}{r}104.766 \\
23.239 \\
69.279\end{array}$ & $\begin{array}{r}237.480 \\
46.284 \\
130.006\end{array}$ & $\begin{array}{l}42.733 \\
6.692 \\
52.892\end{array}$ & $\begin{array}{l}66.952 \\
33.009 \\
59.528\end{array}$ & $\begin{array}{r}109.306 \\
68.701 \\
112.419\end{array}$ & $\begin{array}{r}90.771 \\
-12.647 \\
7.835\end{array}$ & $\begin{array}{l}37.404 \\
-9.770 \\
9.751\end{array}$ & $\begin{array}{r}128175 \\
-22417 \\
17.586\end{array}$ \\
\hline $\begin{array}{l}\text { Nơt Pionero } \\
\text { Oeste }\end{array}$ & $\begin{array}{l}15.058 \\
33.562\end{array}$ & $\begin{array}{l}19.713 \\
7.710\end{array}$ & $\begin{array}{l}34.771 \\
69.272\end{array}$ & $\begin{array}{l}24.820 \\
\text { 90. } .646\end{array}$ & $\begin{array}{l}24.014 \\
52.469\end{array}$ & $\begin{array}{r}48.834 \\
103.116\end{array}$ & $\begin{array}{r}-9.762 \\
-17.084\end{array}$ & $\begin{array}{r}-4.301 \\
-16.760\end{array}$ & $\begin{array}{l}-14.063 \\
-33844\end{array}$ \\
\hline Sudeste & 10.134 & 5.08 & 15.212 & 18.782 & 8.084 & 26.876 & -8.658 & -3.006 & -11.68 \\
\hline & 10.65 & 13.698 & 24.355 & 27.245 & 32.655 & 59.900 & -16.589 & -18.956 & \\
\hline PARANA & 12447 & 29.311 & 639.759 & 34.447 & 322655 & 665.103 & $\mathbf{0}$ & -25.344 & $4-253$ \\
\hline
\end{tabular}

FONTE: IP ARDES.

NOTA: Dados Extraídos de IP ARDES, 2003.

Com relação à infra-estrutura urbana, houve melhorias significativas em todas as mesorregiões do estado, principalmente nas mesorregiões que apresentavam as condições mais precárias em 1991, como na região sul do estado. Com exceção ao sul paranaense, todas as mesorregiões apresentam 90\% ou mais dos domicílios com água encanada. A mesma dinâmica ocorre na energia elétrica, embora somente a mesorregião centralsul do Paraná, que ficou abaixo dos $90 \%$ dos domicílios atendidos (tabela 6).
O consumo de energia cresceu em média $67 \%$ nas mesorregiões paranaenses, e novamente as regiões sul do estado apresentaram maior crescimento em função da base ser muito baixas nestas mesorregiões. Enquanto o sul cresceu a taxas $89,8 \%$, as demais mesorregiões cresceram a $65 \%$. O consumo de energia do setor secundário (indústria) cresceu a valores superiores ao total consumido, com média de $70 \%$, com crescimento mais expressivo na região sul do estado, crescendo o dobro das demais regiões do estado.

TAELLA 6-D OMICÍLIOS ATENDIDOS COM ÁGUA E ENERGIAELÉ TRICA, E CONSUMO DE ENERGIA.

\begin{tabular}{|c|c|c|c|c|c|c|c|c|}
\hline \multirow{2}{*}{ MESORREGẪO } & \multicolumn{2}{|c|}{ ÁQUAENCANADA } & \multicolumn{2}{|c|}{ ENERG|AELÉTECA } & \multicolumn{2}{|c|}{ CONSJWO ENERGAS } & \multicolumn{2}{|c|}{ OONSUWO ENERGAUDLISTHA } \\
\hline & 1991 & 2000 & 1991 & 2000 & 1991 & 2000 & 1991 & 2000 \\
\hline $\begin{array}{l}\text { CentroOdidertal P aanaense } \\
\text { Centro Orienta Paranærese }\end{array}$ & $\begin{array}{l}788 \\
765\end{array}$ & $\begin{array}{l}94,6 \\
92,3\end{array}$ & $\begin{array}{l}88,6 \\
84.9\end{array}$ & $\begin{array}{l}97,6 \\
959\end{array}$ & $\begin{array}{r}282156 \\
1312226\end{array}$ & $\begin{array}{r}369.925 \\
2309017\end{array}$ & $\begin{array}{r}65.554 \\
994.277\end{array}$ & $\begin{array}{r}88.726 \\
1779.922\end{array}$ \\
\hline Cent & 55 & 83 & 67 & 880 & 293491 & 564.377 & 100.928 & 229.327 \\
\hline Mer & 893 & 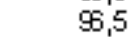 & 9 & 990 & 3.846369 & 6.662 .968 & $18 \bar{X} .980$ & 2913.437 \\
\hline Noroes & 868 & 9,4 & 9 & 994 & 498589 & 751.524 & 7.230 & 166.620 \\
\hline Nort & 90,1 & 9,6 & 96 & 991 & 1.885903 & 2.951 .431 & 564.730 & 865.522 \\
\hline Note Pione & 778 & 94,0 & 91 & 983 & 463551 & 645.721 & 130.826 & 173.079 \\
\hline OesteParanense & 87,7 & $g, 2$ & 93 & 988 & 1.068341 & 1.754 .790 & 200.819 & 407.343 \\
\hline Sud & 56,7 & 80,7 & 73 & 91,3 & 230926 & $494.2 \pi$ & 106.964 & 270.675 \\
\hline Sucbest Paranarae & 722 & 90.8 & 86.2 & 969 & 343982 & 589.988 & 6.780 & 162.895 \\
\hline
\end{tabular}

FONT E: IP ARDES, IBGE.

O tamanho da economia das mesorregiões, medido através do Produto Interno Bruto, mostra que 40,7\% do PIB do estado é gerado na região metropolitana de Curitiba, $16,9 \%$ no Norte Central (principalmente Londrina e Maringá) e 14,5\% no Oeste (Foz do Iguaçu e Cascavel são os expoentes). A produtividade, medida através da razão PIB por PEA, se mostrou maior nas regiões onde o PIB industrial é elevado. Nas regiões onde o PIB agropecuário é maior, a produtividade se mostrou inferior em relação ao demais. A região metropolitana possui a maior produtividade pelo fator trabalho do estado, seguido pela centro oriental.

O desemprego cresceu entre 1991 e 2000 em todas as mesorregiões do estado, ultrapassando dois dígitos em todas as mesorregiões, com exceção ao Sudeste e Sudoeste paranaense. As maiores taxas estão na mesorregião metropolitana de Curitiba, Centro Oriental e Centro Ocidental (tabela 7). 
TAEELA 7-PIB EM MILHARE SDE R\$ ( $M N O$ 2000), DE SEMPREGO E RENDA.

\begin{tabular}{|c|c|c|c|c|c|c|c|c|}
\hline \multirow{2}{*}{ MESORREGẪOO } & \multicolumn{3}{|c|}{ PRODUTO INTE FNO BRIITO } & \multirow{2}{*}{$\begin{array}{r}\text { PRODLIVIDADE } \\
2000\end{array}$} & \multicolumn{2}{|c|}{ DESEMPREGO } & \multicolumn{2}{|c|}{ RENDA } \\
\hline & Acropecuário & Industrial & Servicos & & 1991 & 2000 & 1991 & 2000 \\
\hline Centro Ocidenta Parana日ise & 542283 & 317576 & 727.684 & $10.055, \pi 0$ & $2,0 \%$ & $13,7 \%$ & 390,16 & 522,35 \\
\hline Centro Oriental Paranaense & 741.487 & 1.822307 & 1.488139 & $15.293,43$ & $4,7 \%$ & $14,1 \%$ & 551,38 & 733,53 \\
\hline Centro-SulP aranaense & 686060 & 940645 & 1.00074 & $11.051,04$ & $3,3 \%$ & $11,5 \%$ & 397,24 & 522,96 \\
\hline Metropdtana de Cưtiba & 629376 & 12.340205 & 11.929072 & $16.501,8$ & $5,3 \%$ & $14,7 \%$ & 821,29 & $1.044,89$ \\
\hline Nor oesteParana日se & 788205 & 673629 & 1.264 .142 & $8.660,5$ & $2,5 \%$ & $10,7 \%$ & 394,79 & 540,07 \\
\hline Norte Central Paranax & 1.320 .704 & 3.996917 & 789 & $11.172,15$ & $2,6 \%$ & $12,4 \%$ & 530,13 & 731,76 \\
\hline Nore Piore roP aranmense & 624.251 & 544836 & 1.031 .721 & $8.547,33$ & $2,4 \%$ & $11,9 \%$ & 391,84 & 521,30 \\
\hline OetePagnanse & 1.585867 & 3.707818 & 3.542403 & $15.568, \circledast 6$ & $3,6 \%$ & $12,8 \%$ & 533,60 & 678,57 \\
\hline Sudese Paranaense & 528.496 & 368001 & 60376 & $8.492,20$ & $2,3 \%$ & $8,9 \%$ & 300,87 & 445,58 \\
\hline Sudoeste Paranaense & 907.104 & 520.149 & 974.724 & $9.881,30$ & $1.9 \%$ & $8,4 \%$ & 333,34 & 518,76 \\
\hline
\end{tabular}

FONTE: IPARDES, IBGE.

As regiões com maior participação do PIB industrial (metropolitana de Curitiba, Centro Oriental, Norte Central e Oeste Paranaense) possuem as maiores rendas. As mesorregião Sudoeste e Sudeste do estado apresentaram os maiores crescimentos na renda, $55,6 \%$ e $48,1 \%$ de crescimento respectivamente.

A composição do PIB no estado é $45,1 \%$ de Serviços, $41,3 \%$ de Indústria e
13,7\% de Agropecuária. O PIB de serviços é superior a um terço em todas as mesorregiões, porém é no PIB Industrial e Agropecuária que há as maiores diferenças. A região Sul, com exceção do Centro-sul apresenta maior dinâmica agropecuária, juntamente com a Centro Ocidental. A mesorregião metropolitana de Curitiba, a Centro Oriental e o Oeste Paranaense apresentam maior grau industrial do estado (gráfico 2).

GRÁFICO 2-COMP OSIÇẪO DO PIBDAS MESORREGIỐES EM 2000.

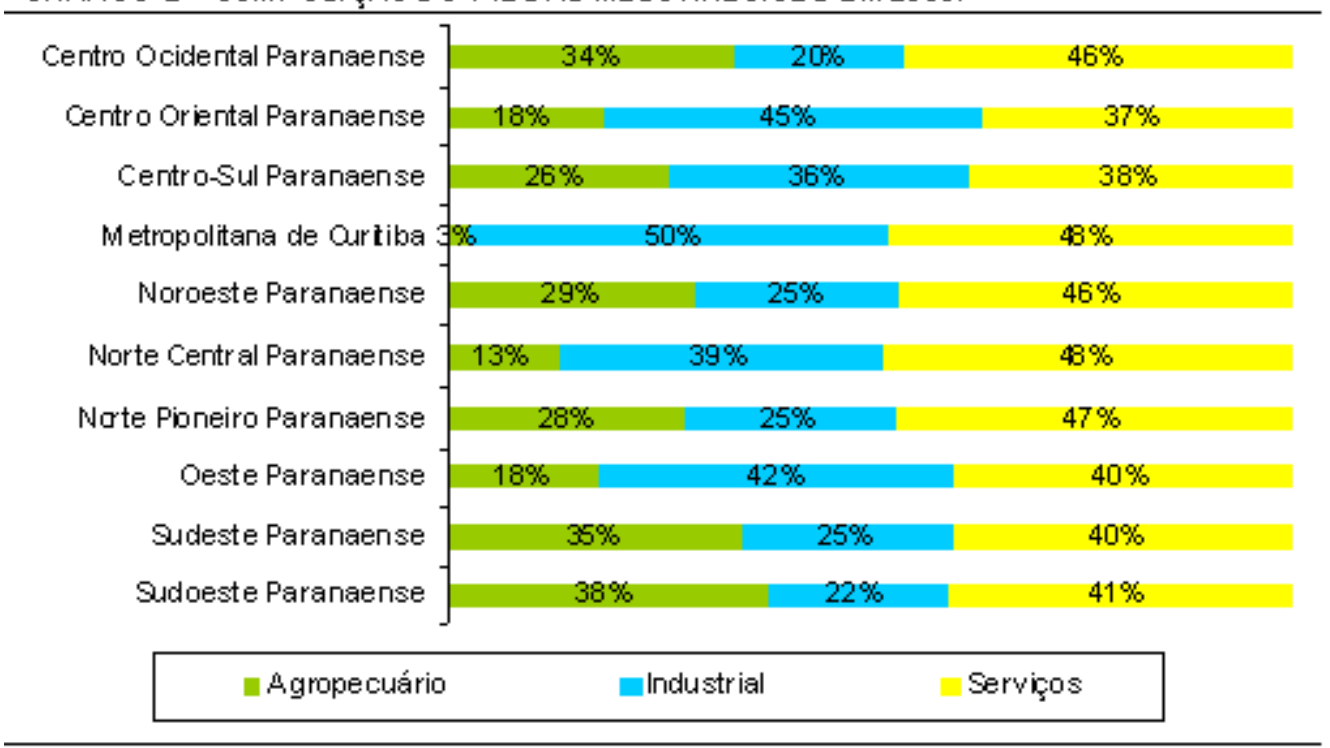

FON TE: IPARDES.

NOT A Dados Trabalhacbs peb Autor.

O número de estabelecimentos industriais da mesorregião noroeste cresceu 95,4\% no período 1990 a 2000, sendo a mesorregião que mais aumentou o número de estabelecimentos em termos relativos. Em termos absolutos, o Norte Central instalou 1.738 estabelecimentos industriais, seguido pela metropolitana de Curitiba 1.318 novos estabelecimentos.
O Noroeste, Norte Central e Oeste Paranaense aumentaram suas participações no emprego do estado ao longo da década de 1990, com a mesorregião metropolitana perdendo 710 pontos básicos na participação do emprego do estado. Contudo, a participação da mesorregião metropolitana no valor adicionado cresceu 451 pontos básicos, 
seguido pelo centro oriental com 443 pontos básicos, enquanto as regiões que aumentaram a participação no emprego, apresenta- ram perda de 161 pontos básicos em média na participação do valor adicionado do estado (tabela 8).

TAEEA 8-ESTABELECIMENTOS, EMPREG OE VALOR ADICIONADO INDUSTRIAIS.

\begin{tabular}{|c|c|c|c|c|c|c|}
\hline \multirow{2}{*}{ MESORREGIỖES } & \multicolumn{2}{|c|}{ ESTABELECIMENTO S (A bs) } & \multicolumn{2}{|c|}{ EMPREGOS(\%) } & \multicolumn{2}{|c|}{$V A(\%)$} \\
\hline & 1990 & 2000 & 1990 & 2000 & 1990 & 2000 \\
\hline Centro Ocidental Paranaense & 347 & 420 & 1,66 & 1,64 & 2,00 & 0,67 \\
\hline Centro-Orient al Paranae ns & 634 & 999 & 8,59 & 7,14 & 6,44 & 10,87 \\
\hline Centro-Sul Paranaense & 550 & 872 & 4,78 & 4,16 & 3,57 & 1,93 \\
\hline M etropolitana de Curitiba & 4.833 & 6. 151 & 44,26 & 37,16 & 60,01 & 64,52 \\
\hline Noro este Par ana ense & 778 & 1.520 & 3,26 & 6,57 & 1,65 & 2,17 \\
\hline Nort e Centr al Par anae nse & 2.753 & 4. 491 & 19,62 & 23,32 & 15,14 & 11,63 \\
\hline Nort e Pione ro P ara naense & 516 & 676 & 3,77 & 3,40 & 3,07 & 1,41 \\
\hline Oeste Paranaen $₫$ & 1.187 & 1. 927 & 6,07 & 7,85 & 5,08 & 3,24 \\
\hline Su deste Paran aense & 653 & 969 & 4,48 & 4,51 & 1,85 & 2,08 \\
\hline Su doeste $P$ ara naense & 602 & 908 & 3,52 & 4,24 & 1,19 & 1,48 \\
\hline TOTAL DOESTADO & 12853 & 18.933 & 100,00 & 100,00 & 100,00 & 100,00 \\
\hline
\end{tabular}

FONTE: R ASMTE, SEFA, IPARDES.

NOTA: DadosE xtraídos de IPARDES (2003a)

A mesorregião metropolitana de $\mathrm{Cu}$ ritiba possui a maior média de anos de estudos do Paraná, distando 1,2 anos de estudos em relação à segunda mesorregião neste ranking, Norte Central que aumentou a média de anos de estudo em 1,3 junto com Oeste Paranaense. As mesorregiões com maior média de anos de estudo são as mesmas que apresentam a maior dinâmica industrial e grau de urbanização.

Os professores de ensino fundamental com ensino superior representavam, em média, 25,1\% dos professores no Paraná em 1991 e passou para 31,8\% em 2000. As mesorregiões Centro-Sul (que apresentou decrescimento desta proporção), Oeste e Sudeste paranaense apresentam os menores índices de professores com ensino superior, cuja média foi $25,7 \%$. A região norte (Norte Pioneiro e Norte Central) possui os maiores índices do estado, onde é média é de 38,8\% dos professores do ensino fundamental.

As mesorregiões Norte Central e Noroeste paranaense possuem os maiores índices de médicos por mil habitantes, com 25,4 e 21,6 médicos a cada mil habitantes. O Sudeste, Centro Oriental e Centro Sul, que apresentou uma redução no índice de médicos por mil habitantes, são as mesorregiões com menor índice do Estado (tabela 9).

TAELA 9 - ANOS DE ESTUDOS DAS PESSOAS COM 25 ANOS OU MAS, PROFESSORES DO ENSNO FUNDAMENTAL COM ENSINO SUP ERIOR, MÉ DICOS POR MIL HAET ANTE SE LONGE MD ADE

\begin{tabular}{|c|c|c|c|c|c|c|c|c|}
\hline \multirow[t]{2}{*}{ ME SORREGIAि̃O } & \multicolumn{2}{|c|}{$\begin{array}{l}\text { ANOSDE } \\
\text { ESTUDOS }\end{array}$} & \multicolumn{2}{|c|}{$\begin{array}{l}\text { PROFESSORES COM } \\
\text { ENSINO SUPERIOR }\end{array}$} & \multicolumn{2}{|c|}{$\begin{array}{c}\text { MÉDICOS (por } \\
1.000 \mathrm{hab})\end{array}$} & \multicolumn{2}{|c|}{$\begin{array}{l}\text { ESP ERANCAA } \\
\text { DE VIDA }\end{array}$} \\
\hline & 1991 & 2000 & 1991 & 2000 & 1991 & 2000 & 1991 & 2000 \\
\hline Centro O cidental Paranaense & 3,6 & 4,8 & 22,5 & 34,6 & 7,8 & 10,5 & 64,1 & 67,0 \\
\hline Centro O riental $P$ aran ae $n$ se & 4,4 & 5,5 & 25,8 & 29,9 & 2,5 & 4,1 & 62,8 & 68,3 \\
\hline Centro-SulParanaense & 3,6 & 4,6 & 22,5 & 22,2 & 7,1 & 3,9 & 63,6 & 67,5 \\
\hline Metropolitana de Curitiba & 6,2 & 7,2 & 33,8 & 34,8 & 10,5 & 12,2 & 67,2 & 70,7 \\
\hline Noroeste Paranaense & 3,8 & 5,0 & 21,2 & 30,5 & 14,7 & 21,6 & 66,0 & 70,1 \\
\hline Norte Central Paranaense & 4,7 & 6,0 & 30,8 & 39,5 & 20,5 & 25,4 & 66,6 & 70,9 \\
\hline Norte Pioneiro Paranaense & 3,9 & 4,9 & 23,5 & 38,0 & 13,8 & 15,4 & 64,7 & 68,6 \\
\hline O este Paranaense & 4,5 & 5,8 & 29,1 & 27,4 & 12,6 & 14,4 & 65,9 & 70,1 \\
\hline Sudeste Paranaense & 3,9 & 4,8 & 21,6 & 27,6 & 2,6 & 4,8 & 64,2 & 68,2 \\
\hline Sudoeste Paranaense & 4,0 & 5,1 & 22,8 & 33,2 & 8,7 & 13,2 & 67,0 & 71,7 \\
\hline
\end{tabular}

FONTE: IPE ADATA, IPARDES. 
A esperança de vida paranaense cresceu quatro anos entre 1991 a 2000, passando de 65,9 anos para 69,9 anos. As mesorregiões apresentaram esperança de vida próxima de 70 anos para as mesorregiões que possuem um índice de médicos por mil habitantes superiores a 10, embora o Centro Ocidental e o Norte Pioneiro não possuírem a mesma característica.

A desigualdade no Paraná permaneceu nos mesmos patamares de 1991, embora algumas mesorregiões tenham crescido, como a metropolitana de Curitiba e algumas tenham decrescido, como Sudoeste. Porém, todas as mesorregiões apresentaram redução das pessoas pobres ${ }^{2}$, com algumas mesorregiões reduzindo significativamente este índice, como Noroeste, Norte Pioneiro, Sudeste e Sudoeste Paranaense (tabela 10).

Com relação à violência, mensurada através da taxa de homicídio a cada cem mil pessoas, apresentou comportamentos distintos em sua maioria, embora que em três grandes mesorregiões em termos de tamanho da economia, apresentaram crescimento das taxas de homicídios, além de serem as regiões com maior índice de homicídio. São elas: Metropolitana de Curitiba $(24,3)$, Oeste $(30,1)$ e Norte Central $(11,4)$. A mesorregião Centro Sul possui o segundo maior índice de violência do Paraná, apesar da redução entre 1991 e 2000.

TAEE LA 10-ÍNDIC E DE GINI,PESSOAS P OERES E T AXA DE HOMICÍDIO..

\begin{tabular}{l|r|r|r|r|r|r}
\hline \multirow{2}{*}{ MESORFE GIỐES } & \multicolumn{2}{c|}{ ÍNDICE DE GINI } & \multicolumn{2}{r|}{ PESSOA SP OBRES (\%) } & \multicolumn{2}{r}{ TAXA DE HOM ICIDIO } \\
\cline { 2 - 7 } & 1991 & 2000 & 1991 & 2000 & 1991 & 2000 \\
\hline Centro O cident al Paranaense & 0,56 & 0,57 & 46,8 & 35,9 & 21,2 & 7,5 \\
Centro Orient al Paranaense & 0,57 & 0,59 & 39,2 & 29,7 & 13,1 & 15,1 \\
Centro-Sul Paranaense & 0,62 & 0,63 & 54,6 & 43,2 & 30,7 & 25,5 \\
Metrop olit ana de Curitiba & 0,52 & 0,56 & 18,5 & 16,0 & 13,8 & 24,3 \\
Noroeste Paranaense & 0,55 & 0,54 & 44,1 & 26,1 & 11,7 & 10,6 \\
Norte Central Paranaense & 0,52 & 0,54 & 28,1 & 19,0 & 9,7 & 11,4 \\
Norte Pioneiro Paranaense & 0,55 & 0,55 & 45,1 & 30,9 & 9,4 & 9,7 \\
Oeste Paranaense & 0,57 & 0,58 & 35,5 & 24,2 & 20,7 & 30,1 \\
Sudeste Paranaense & 0,57 & 0,57 & 55,7 & 39,3 & 10,9 & 12,2 \\
Sudoe ste Paranaense & 0,59 & 0,56 & 50,5 & 29,4 & 12,7 & 10,8 \\
\hline
\end{tabular}

FONTE: IPEADATA, IPARDES.

NOTA: Dados T rabalkados pelo Autor.

Os indicadores selecionados na tabela 11 mostram a melhora em todas elas, que poderiam ser alocadas em algumas outras dimensões. A região sul do estado apresentou as maiores melhorias nos indicadores de qualidade de vida, como Água Encanada e Banheiro, Energia e Geladeira, Coleta de lixo e redução dos domicílios subnormais. Os indicadores de riqueza, Energia e Televisão, três bens duráveis ou mais e telefone, apresentaram as maiores melhorias na mesorregião Oeste, seguida pelo Norte Central e Metropolitana de Curitiba. Somente
Energia e Televisão que a região sul do estado apresentou as maiores médias de crescimento.

As mesorregiões com maior dinâmica industrial possuem mais domicílios com indicadores positivos, excetuando domicílios subnormais nas mesorregião metropolitana de Curitiba, Centro Oriental e Oeste Paranaense. Apenas o Norte Central, que possui elevada dinâmica industrial reduziu os domicílios subnormais para aproximadamente zero, e a mesorregião oeste com redução para $0,4 \%$ de domicílios subnormais. 
TAELA 11 - DOMICÍLIOS COM ÁGUA ENCANADAE GMNHEIRO, ENERGIA E GELADEIRA, ENERGIA E TELEVISÃO, PELOMENOS 3 BENSDURÁVEIS, COLETA DE LIXO, TELEF ONE E SUENORMASS.

\begin{tabular}{|c|c|c|c|c|c|c|c|c|}
\hline \multirow[t]{2}{*}{ MESORREGIỐES } & \multicolumn{2}{|c|}{$\begin{array}{c}\text { AGUA ENCANADA E } \\
\text { BANHEIRO }\end{array}$} & \multicolumn{2}{|c|}{$\begin{array}{l}\text { ENER GIA, E } \\
\text { GELADEIRA }\end{array}$} & \multicolumn{2}{|c|}{$\begin{array}{l}\text { ENERGIA E } \\
\text { TELE W SẤO }\end{array}$} & \multicolumn{2}{|c|}{$\begin{array}{l}\text { PELO MEN } O S 3 \\
\text { BENS DURAYEIS }\end{array}$} \\
\hline & 1991 & 2000 & 1991 & 2000 & 1991 & 2000 & 1991 & 2000 \\
\hline Centro Ocidental Paranaense & 70,9 & 88,0 & 64,8 & 86,0 & 68,7 & 87,9 & 24,2 & 40,6 \\
\hline Centro $\alpha$ rientalP ar anæense & 62,0 & 82,0 & 59,4 & 82,1 & 66,4 & 87,0 & 25,7 & 46,4 \\
\hline Centro-Sul Paranaense & 42,5 & 67,6 & 45,5 & 71,6 & 49,2 & 74,7 & 17,2 & 35,9 \\
\hline Metropolitana de Curitiba & 82,5 & 92,8 & 80,9 & 93,4 & 82,5 & 92,9 & 42,0 & 64,1 \\
\hline Noroese P aranaense & 79,3 & 92,1 & 76,9 & 93,1 & 78,0 & 92,1 & 27,6 & 43,6 \\
\hline Norte Central P aranaense & 84,5 & 94,9 & 81,2 & 94,4 & 81,4 & 92,6 & 36,4 & 62,1 \\
\hline Norte Pioneiro Paranaeree & 67,4 & 88,2 & 64,9 & 87,3 & 72,4 & 89,4 & 24,7 & 41,4 \\
\hline Oeste $P$ araraense & 81,7 & 94,2 & 80,4 & 93,5 & 76,2 & 90,7 & 31,9 & 60,8 \\
\hline Sudeste $P$ aranaense & 43,4 & 65,7 & 51,6 & 77,1 & 54,2 & 81,0 & 21,1 & 36,4 \\
\hline Sudoeste $P$ aranaense & 66,0 & 82,7 & 71,7 & 911 & 62.5 & 86.1 & 25,1 & 48,3 \\
\hline
\end{tabular}

\begin{tabular}{l|r|r|r|r|r|r}
\hline \multirow{2}{*}{ ME SORREGIỖES } & \multicolumn{2}{|c|}{ COLET A DE LIXO } & \multicolumn{2}{c|}{ TELEF ONE } & \multicolumn{2}{c}{ SUBNORMAIS } \\
\cline { 2 - 7 } & 1991 & 2000 & 1991 & 2000 & 1991 & 2000 \\
\hline Centro Oddental P aranaense & 73,3 & 93,1 & 11,8 & 21,6 & 0,9 & 0,5 \\
Centro Oriental P aran aense & 79,0 & 95,6 & 17,6 & 32,5 & 4,3 & 2,6 \\
Centro-Sul Paran aense & 56,2 & 91,4 & 10,2 & 22,7 & 0,3 & 0,0 \\
Metrop olitana de Cur tiba & 89,5 & 98,4 & 33,7 & 55,0 & 5,9 & 5,6 \\
Noroeste Paranaense & 76,2 & 95,5 & 15,1 & 25,3 & 0,4 & 0,2 \\
Nort e Central Paranaense & 86,2 & 97,1 & 25,7 & 49,7 & 1,0 & 0,0 \\
Nort e Pioneiro Paran aense & 83,4 & 96,4 & 14,0 & 24,9 & 0,6 & 0,3 \\
Oeste Paranaense & 80,2 & 96,1 & 16,7 & 48,5 & 1,2 & 0,4 \\
Sudese Paranaense & 64,1 & 92,7 & 9,5 & 15,5 & 0,8 & 0,0 \\
Sudoese Paranaense & 61,6 & 93,0 & 12,8 & 30,4 & 0,3 & 0,0 \\
\hline
\end{tabular}

FONTE: IPEADATA, IP ARDES.

NOTA: DadosT rabalkados pelo Autor.

Desta forma, ao longo da década de 1990 as transformações produtivas no Paraná impactaram em diversas áreas da sociedade. A dinâmica industrial contribuiu para melhorar alguns indicadores socioeconômicos, porém também houve alguns impactos negativos, como desemprego e concentração populacional em grandes centros.

\section{Conclusões}

O propósito do artigo era discutir as diferenças constituídas no processo de reestruturação produtiva do Paraná na década de 1990 para as diversas mesorregiões. Os resultados trouxeram contribuição para a academia, para o Estado e para as organizações que refletem e interferem no processo de desenvolvimento paranaense, como Federações da Indústria Paranaenses (FIEPPR). Para academia, por explorar o controverso debate sobre desenvolvimento local e a importância de intervenção do Estado para busca de melhoria nas condições socioeconômicas para diferentes regiões, com histórias e necessidades específicas. Para o Estado e organizações envolvidas com o processo de desenvolvimento paranaense por refletir os reais impactos dos investimentos nas diferentes regiões do Paraná, em que se mostrou a necessidade de avaliar e atrair investimentos para incentivar o crescimento associado a redução da desigualdade regional, o que não aconteceu.

O objetivo era avaliar as mudanças socioeconômicas e territoriais a partir das transformações produtivas do Paraná e das suas mesorregiões na década de 1990 e mostrou-se que o aporte de investimentos foi direcionado para indústria automobilística. Esse novo capital transformou tanto a pauta de produção quanto a de exportação industrial e se localizou na região metropolitana de Curitiba pela infra-estrutura favorável e pela existência de uma base metal-mecânica. Esta base não foi aproveitada o suficiente (FARAH, 2002), para otimizar os ganhos dos produtores locais, mas que incentivou a atração de investimento para região. 
As reflexões sobre os indicadores socioeconômicos, contudo, mostraram que esses ganhos foram concentrados na região metropolitana, mas foi uma década com forte melhora em vários indicadores, apesar de não ter uma mudança significativa no índice de Gini, que mede a desigualdade de renda. A elevação da desigualdade, devido ao desemprego e a maior concentração de renda pelos mais ricos, mantiveram o crescimento da violência analisada a partir da taxa de homicídio. Contudo, o maior grau de urbanização e a demanda por mão de obra qualificada melhoraram a educação da população, além da criação de novas universidades no estado e da alteração do sistema educacional do ensino fundamental, reduzindo a evasão escolar e aumentando a quantidade média de anos de estudos da população adulta, ou seja, houve uma melhora quantitativa na educação.

Apesar da tendência do estado mostrar melhoria nos indicadores, os resultados entre as mesorregiões diferem. É possível notar que houve concentração de renda nas grandes cidades onde a participação industrial é maior, como a região metropolitana, Norte Central e Centro Oriental. Com isso, se valida a hipótese que o Paraná tenham mostrado melhorias econômicas em 2000 em relação a 1991, mas a mudança ficou concentrada na região metropolitana de Curitiba e nas grandes cidades. Isso decorreu de uma política de incentivo ao processo de modernização produtiva e novos investimentos, sem a preocupação de desconcentração regional, já historicamente existente entre as mesorregiões do Estado.

A partir dos resultados alcançados, torna-se importante destacar duas limitações desse trabalho. A primeira foi tratar o desenvolvimento local sob a ótica das mesorregiões, desconsiderando que mesmo cada município tem a sua própria dinâmica e o impacto do processo de reestruturação produtiva pode ter sido, obviamente, diferente nestes em cada município de uma mesmo mesorregião. Contudo, esta limitação se torna necessária por avaliar uma intervenção em nível estadual e os resultados apresentam um delineamento para estudos mais específicos. A segunda limitação foi tratar o processo de desenvolvimento a partir da esfera territorial (espacial), econômica e social, sem abordar questões como mudança institucional, cultural e ambiental. Importantes temas mas que ficaram com proposta para novos estudos.

Assim sendo, como proposta de continuidade deste trabalho, cabe ainda avaliar e desenvolver políticas destinadas a redução das disparidades entre as cidades do Paraná com maior disseminação das ações públicas para o estímulo do processo de desenvolvimento local. Outro estudo interessante seria da efetividade destas políticas públicas com intuito de estabelecer de forma objetiva qual a intervenção pretendida e que se resultados se alcançou. Outro projeto importante seria de integração dos planos estratégicos municipais e do Estado com os estabelecidos legalmente (Plano Plurianual, Lei de Diretrizes Orçamentárias e Lei de Orçamento Anual) com intuito de avaliar a efetividade dos resultados alcançados a partir do investimento público. Estes estudos teriam um enfoque local, em busca do amadurecimento do processo de desenvolvimento local dos municípios a partir de uma intervenção pública efetiva para redução das desigualdades e criação de oportunidades para descentralização econômica do Estado, com impactos sociais positivos. Por isso, sugerem-se também avaliações na esfera municipal, com estudos de caso, para aumentar a profundidade da análise e observar as diferentes dinâmicas em cada local.

\section{Notas: \\ ${ }^{1}$ As mesorregiões são as estabelecidas pelo IBGE e tratadas por Ipardes (2004). \\ ${ }^{2}$ Percentual de pessoas com renda domiciliar per capita inferior a $R \$ 75,50$, equivalentes a $1 / 2$ do salário mí- nimo vigente em agosto de 2000.}

\section{Referências}

AJARA, César. As Difíceis vias para o desenvolvimento sustentável: gestão descentralizada do território e zoneamento ecológico-econômico. Textos para discussão 8. Rio de Janeiro: Escola Nacional de Ciências Estatísticas, 2003.

BAUMANN, Renato (org.). O Brasil e a Economia Global. Rio de Janeiro: CAMPUS, 1996.

BELLEN, Hans Michael van. Desenvolvimento Sustentável: Uma Descrição das Principais Ferramentas de Avaliação. In: Ambiente e Sociedade (7), Campinas, p. 67-87, n. 1, 2004.

BLACKELY, Edward J. Planning Local Economic Development: theory and practice. 2 ed. USA: Sage Publications, 1994. 
CAMARGO, Ana Luiza de Brasil. Desenvolvimento Sustentável: Dimensões e Desafios. Campinas: Papirus, 2003.

CASTRO, Demian. Mudança, Permanência e Crise no Setor Público Paranaense: Um Balanço da Trajetória Estadual na Segunda Metade do Século XX. Campinas, 2005. Tese (Doutorado em Economia - Instituto de Economia, Universidade de Campinas)

CASTRO, Demian; LEÃO, Igor Z. C. C. Uma Análise da Economia Paranaense nas últimas décadas. In: IPARDES. Boletim da Conjuntura \& Tecnologia (10). Curitiba, mai/ jun. 2005.

CLAYTON, Antony M.H.; RADCLIFFE, Nicolas J. Sustainability: A System Approach. Cambridge, MA: Westview, 1996.

DRESNER, Simon. The Principles of Sustainability. London: Earthscan, 2002.

FARAH Jr., Moisés Francisco. Uma proposta de estruturação da capacidade competitiva das pequenas e médias empresas metal mecânicas da região de Curitiba através da formação de um cluster. Florianópolis, 2002. Tese (Doutorado em Engenharia de Produção) - Setor Ciências Exatas, Universidade Federal de Santa Catarina).

FIRKOWSKI, Olga Lúcia Castreghini de Freitas. A Nova Lógica de Localização Industrial no Aglomerado Metropolitano de Curitiba. In: Revista Paranaense de Desenvolvimento (103), Curitiba, p. 79-100, jul./dez. 2002.

FOLADORI, Guillermo. Avanços e Limites da Sustentabilidade Social. In: Revista Paranaense de Desenvolvimento (102), Curitiba, p. 103-113, jan./jun. 2002.

FROEHLICH, José Marcos. O “Local” na Atribuição de Sentido ao Desenvolvimento. In: Revista Paranaense de Desenvolvimento (94), Curitiba, p. 87-96, maio/dez. 1998.

GRAAF, H.J.; KUERS, W.J.; MUSTERS, C.J.M. Sustainable Development: Looking for New Strategies. Ecological Economics, 1996.

GIL, A. C. Métodos e técnicas de pesquisa social. 5. ed. São Paulo: Atlas, 1999.

HAQUE, M. Shamsul. Environment Discourse and Sustainable Development: Linkages and Limitations. Ethics and Environment, vol. $5 \mathrm{n}^{\mathrm{o}}$ 1, 2000.

IPARDES. Crescimento, Reestruturação e Competitividade Industrial no Paraná - 1985 - 2000. Instituto Paranaense de Desenvolvimento Econômico e Social. Curitiba: IPARDES, 2002.

- A Integração Comercial da Indústria Paranaense nos Anos Noventa. Instituto Paranaense de Desenvolvimento Econômico e Social. Curitiba: IPARDES, 2002.

Leituras Regionais: Mesorregiões Geográficas Paranaenses: Sumário Executivo. Instituto Paranaense de Desenvolvimento Econômico e Social. Curitiba: IPARDES, 2004.

Tipologia dos Municípios Paranaenses Segundo Indicadores Socioeconômicos e Demográficos. Instituto Paranaense de Desenvolvimento Econômico e Social. Curitiba: IPARDES, 2003.

LENCIONI, Sandra. Re-configurações territoriais: reestruturações econômicas e sócio-espaciais. In: X ENCONTRONACIONAL DA ASSOCIAÇÃONACIONAL DEPÓSGRADUAÇÃOE PESQUISA EMPLANEJAMEN-
TO URBANO E REGIONAL - ANPUR, 2003, Belo Horizonte. Anais... Belo Horizonte: Associação Nacional de Pós-Graduação e Pesquisa em Planejamento Urbano e Regional, 2003, p. 1-13.

LOURENÇO,Gilmar Mendes. A Economia Paranaense em Tempos de Globalização. Curitiba: Ed. do Autor, 2003.

. A Economia Paranaense nos Anos 90: Um Modelo de Interpretação. Curitiba, PR: Ed. do Autor, 2000

MARCONI, M. A.; LAKATOS, E. M. Técnicas de pesquisa. 3. ed. São Paulo: Atlas, 1996.

MERCADO, Aléxis; CORDOVA, Karenia. Desarollo Sustentable - Industria: más controvérsias menos respuestas. In: Ambiente $\mathcal{E}$ Sociedade (8), Campinas, p. 27-50, jan.-jun. 2005.

REGO, José Márcio; MARQUES, Rosa Maria (Org.). Economia Brasileira. São Paulo, SP: Saraiva, 2003.

SACHS, Ignacy. Ecodesenvolvimento: Crescer sem destruir. São Paulo, SP: Revista dos Tribunais, 1986.

Estratégias de Transição para o Século XXI: Desenvolvimento e Meio Ambiente. São Paulo: Nobel, 1993.

SAMPAIO, Armando Vaz. O Mercado de Trabalho no Estado do Paraná entre 1992 e 2003. Instituto de Pesquisa Econômica Aplicada. Brasília: IPEA, 2005.

SILVA, Christian Luiz da. Investimento Estrangeiro Direto: da dependência à globalização. Rio de Janeiro: Fundo de Cultura, 2005.

Desenvolvimento sustentável: um conceito multidisciplinar. In: SILVA, CL; MENDES, JTG (Org.). Reflexões sobre o Desenvolvimento Sustentável: agentes e interações sob a ótica multidisciplinar. 1 ed. Rio de Janeiro: Vozes, p. 11-40, 2005.

SILVA, Christian Luiz da; FARAH Jr, Moisés Francisco. Economia e Política Industrial Paranaense: uma avaliação crítica da década de 1990. Revista de Desenvolvimento Econômico (9). Salvador, p. 17-26, jan. 2004.

SOTO TORRES, M. Dolores; FERNÁNDEZ LECHÓN, Ramón. Feedback Process in Economic Growth: relations between hours worked and labour productivity. Proceeding... Conference System Dinamics, p. 1-20. Disponível em: www.systemdynamics.org/ conferences/2006/proceed/papers/soto-170.pdf. Acesso em: dez. 2006.

SOUZA, Marcelo L. Algumas notas sobre a importância do espaço para o desenvolvimento social. In: Revista Território (3), p.14-35, 1997.

SOUZA, Nali de Jesus. Desenvolvimento Econômico. São Paulo, SP: Ed. Atlas, 1999.

VASCONCELOS, José Romeu de (coord.); CASTRO, Demian. Paraná: economia, finanças públicas e investimentos nos anos 90. Instituto de Pesquisa Econômica Aplicada. Brasília: IPEA, 1999.

VAZ, Maria Teresa de Noronha Vaz. Desenvolvimento regional e inovação empresarial: o impacto do desenvolvimento local nas determinantes de inovação das pequenas empresas. In: Revista Paranaense de Desenvolvimento (108), Curitiba, p.7-24, jan./jun. 2005.

VIVIEN, Franck-Dominique. Le développement soutenable. Paris: Ed La Découverte, 2005. 